ISBN 978-81-936279-5-2

12th International Conference on Business, Education, Humanities and Interdisciplinary Studies

(BEHIS-18)

Zagreb (Croatia) May 11-12, 2018

\title{
Marketing Mix Factors Affecting Healthy Eating Behavior
}

\author{
Dr. Tosaporn Mahamud and Walaikaew Tungtorniran
}

Graduate School of Business Administration, Kasembundit University, Bangkok, Thailand

\begin{abstract}
Studying Marketing mix factors affecting healthy eating behavior. The purpose is to study. Consumer behavior in buying healthy food.And marketing mix factors affecting healthy eating behavior. The population in the study is Those who use DRESSED restaurant service at Exchange Tower Asoke selected 197 samples by using data collection tools. The questionnaire was used to collect data. The data were analyzed by percentage, mean, T-test, ANOVA, Regression and Chi-square.The study indicated that Most respondents were female from 21 to 40 years old. And a career as a private employee. The marketing mix of products and prices is at a high level, with emphasis on The quality of the ingredients used in cooking and the variety of prices to choose from. Distribution channels and marketing promotion were at medium level. Healthy eating habits Mostly choose to consume foods that are low in calories. Eat in dinner And eat clean food for 1-2 years. Buy a clean meal by famous people. Get clean information from the internet and buy clean foods to keep you healthy. Good shape

The results of the hypothesis test showed that Different gender personal factors. Affecting the buying behavior of healthy foods is not different. And personal factors of age. Education Different career affecting the buying behavior of healthy foods is different. Personal factors in product marketing are those that are used to cook food, quality ingredients, and price. Most food prices are cheaper than other restaurants in the area.And there are a variety of prices to choose from. Marketing promotion is a discount card for regular customers. Influence on healthy eating behavior. At a significant level of 0.05. And personal factors related to age are correlated with food buying behavior, the type of healthy food consumed on a regular basis. To buy clean food. Time to choose healthy foods. Food information awareness And the time to eat healthy food to date. Career is related to the duration of healthy eating to the present and the purchase of clean food. The level of education correlated with the purchase of clean food. Food information awareness and clean food. At a significant level of 0.05 .

Suggestions for the study The entrepreneur should pay attention to the selection of quality raw materials for cooking healthy food. Cleanliness And the beauty of the food set. To be suitable for quality. Various prices are displayed in the menu. Organize a knowledgeable staff on clean food to advise customers on how to buy clean foods that are truly beneficial to customers. There are public relations of food distribution through various channels that reach the target customers, such as through channels. Social media (Facebook, Instregram, Line)
\end{abstract}

Keywords: consumer behavior Marketing Mix Factor

\section{Introduction}

Clean food is the least processed and processed food. The most natural. To keep the raw materials to maintain the nutrients. Clean up does not mean that. Must eat only fresh. In fact, it is impossible. Cooked and heat processed foods It can be safe and clean. Because heat helps to kill germs. And the cooking process makes the food is delicious and more appetizing. Eating healthy for better health. But eating clean. If you do not eat properly, it is a danger as well. Eating right and healthy food better. Consumers should choose to consume food in the diet of five groups. Clean food will not be useful as it should not reduce the food processing. Eating clean Pay attention to how to eat regularly. The students are interested to study. Marketing mix factors affecting healthy eating behavior. To find out about the factors that affect the purchase of healthy food and to benefit those who are interested in doing business for health lovers, it is used as a guideline to improve the service of healthy food distribution. next 


\section{Purpose of Study}

1. To study consumers' behavior in buying healthy food.

2. To study marketing mix factors affecting healthy eating behavior.

\section{Scope of Study}

1. The content of the marketing mix theory is 4P's product (Product)

Price (Distribution) (Place and Promotion) and decision-making behavior. When What Whom and How

2. Population and sample used in this study is Healthy people At DRESSED restaurant, Exchange Tower, Asoke chose 197 samples.

3. Duration of study during November BE 2560 - BE BE 2561

\section{The benefits of the Study}

1. The marketing mix factors affecting the healthy eating behavior.

2. Make healthy eating habits.

3. The results of the study can be used as a guideline for the development of healthy food distribution.

\section{Assumptions of the study}

1. Different personal factors. Affecting the buying behavior of different healthy foods.

2. Marketing Mix Factor Influence on healthy eating behavior.

3. Personal factors correlated with healthy eating behavior.

\section{Theoretical and Literary Concepts}

Marketing mix or 4P's. Or composition of the marketing mix. It is a stimulus or marketing stimulus that affects the buying decision process. Contain with

1. Product

2. Price

3. Place

4. The promotion

\section{Question 7 questions (6W1H) to find 7 answers about Consumer Behaviour}

\begin{tabular}{|c|l|}
\hline (6W1H) & \multicolumn{1}{c|}{ Answer (7Os) } \\
\hline 1.Who constitutes the market? & $\begin{array}{l}\text { Occupational characteristics of the consumer.1. geography 2. demography 3. Psychology 4. } \\
\text { Behavior }\end{array}$ \\
\hline 2. What does the market buy? & What objects consumers want to buy? 1. Product Features 2. Product Components \\
\hline 3. Why does the market buy? & Objectives to meet the needs. 1. body 2. psychology \\
\hline $\begin{array}{c}\text { 4. Who participates in the } \\
\text { buying? }\end{array}$ & $\begin{array}{l}\text { Organizations The role of the influential group 1. The initiator 2. The influencer 3. The } \\
\text { decision maker 4. The buyer 5. The user }\end{array}$ \\
\hline 5. How does the market buy? & $\begin{array}{l}\text { Operations steps to make a purchase. } \\
\text { 1. Problem recognition 2. Data search 3. Evaluate alternatives 4. Make a purchase }\end{array}$ \\
\hline 6. When does the market buy? & Occasions of buying opportunities 1. What month / day 2. Special occasions / festivals \\
\hline 7. Where does the market buy? & $\begin{array}{l}\text { Outlets Where to buy products / services } \\
\text { 1. Department Store 2. Supermarket 3. Shop, etc. }\end{array}$ \\
\hline Saree wonmonta (BE.2551 : 36-38) &
\end{tabular}

\section{Conceptual framework}

1. Personal Information Name Sex Age Vocational Education 
2. Marketing Ingredients Product, pricing, channels, promotion,

3. Variable according to type of food clean, The time to clean food, Choose to buy food by any person, Where to get information, What to buy clean food,

\section{Research Methodology}

Quantitative study using questionnaire instrumental To collect sample data.

DRESSED at Exchange Tower, Ashoka, 11.00 - 14.00 hrs. In February BE 2561197 people

\section{Method Research Data}

1. Data collected from Studying from various sources including textbooks, papers and other research findings. Associated

2. Information obtained from Responding Of the target audience And get yourself back. Complete the check. To ensure that the questionnaire is complete and can be analyzed for further information.

\section{Data Analysis}

Processed data from the questionnaire by computer program by Percentage and Mean. Microsoft Excel, a program for pie chart and bar chart. Describe the result The results from the chart are presented for analysis of the variables.

\section{Transcript Personal information}

The majority of respondents were female. Age between 21-40 years old. And a career as a private employee.

\section{- Marketing mix factors affecting healthy eating behavior.}

The product has found that the overall average is very important. Sort by: Variety of food items to choose from. Raw materials used for cooking are quality ingredients. Organize and decorate delicious food. And the food tastes delicious, respectively.

Price, the overall average is very important. Sort by: There is a clear display of food prices in the menu. The price is reasonable. Quantity and quality of food Food prices are cheaper than other restaurants nearby. There are several levels to choose from.

On the place of the distribution channel, the average value of the medium is moderate. Sort by: The location of the shop is convenient, convenient access to many ways. There is sufficient parking space and safe, respectively.

The promotion of marketing (Pomotion) found that the overall average is important in the medium level is the discount card for regular customers.

\section{Healthy Eating Habits}

Healthy foods that are regularly eaten are found to be the least calorie eaters, followed by those who eat junk food. The food is home. And they are vegetarian, respectively.

At the time of choosing healthy foods, it was found that eating the most during dinner. Secondly, those who eat the wrong course. Those who eat at every meal. Those who eat during breakfast. And those who eat at lunch time, respectively.

How long does it take to clean healthy food? It was found that the period of 1-2 years was the most, followed by the period of consumption of food, 3-4 years, the duration of consumption of food for 5 years and the duration of consumption of food for not more than 1 year, respectively. 
Participants in the decision to buy healthy food found that those who choose to buy clean food by famous people, later bought by friends. Purchased by relatives / close friends And buy by the person in the ad, respectively.

The sources of information on food cleanliness were found to be the most informed about clean food from the Internet, followed by friends. Recognize relatives / close ones TV / Radio Perception Recognition of books and journals Perceived by doctors / pharmacists And recognize the dealer. Show Booth in Order

\section{Hypothesis Testing Results}

Based on the hypothesis testing of different personal factors. The results of the tests using $\mathrm{t}$-test / ANOVA showed that the factors Persons with age, education and occupation the difference in the behavior of different health food choices. For personal reasons, gender different Affecting the buying behavior of healthy foods is not different. Based on hypothesis testing, marketing mix factors Influence on healthy eating behavior by using regression showed that price of food was mostly cheaper than other restaurants in the vicinity. There are many price levels to choose from, 2nd and 3rd rank products. Raw materials used in cooking as a raw material influenced healthy eating behavior. Sig value was 0.044 0.021 and 0.014 , respectively.

From the hypothesis testing, personal factors correlated with healthy eating behavior. The Chi-square test showed that the age was related to the purchase behavior. Age 1 was associated with food buying behavior. The second largest and most frequently consumed food item was related to food purchasing behavior. The occupation was correlated with food buying behavior.

Age correlated with food purchasing behavior. The third most important item was cleanliness. Sig was 0.0310 .0020 .000 , respectively.

\section{Discussion of Results}

Studying Marketing mix factors affecting healthy eating behavior. The participants included the following issues.

Sexual factors Individuals with different sexes have no effect on healthy eating behavior. Natree jhutom (2559) studied the decision to buy healthy foods. The effect on the decision to buy healthy food (Clean Food) is not different.

Personal factors with age the difference in the behavior of healthy food selection. The results are consistent with the findings of matarinya mabangklu (BE2558). The consumers of healthy food in Bangkok met the age of consumers. The difference in the health of consumers in Bangkok. The difference in marketing promotion in terms of price was statistically significant at the .05 level.

Personal Facts with Education Level the difference in the behavior of different health food choices. In line with the findings of matarinya mabangklu (BE2558), the study of consumers' decision to buy healthy food in Bangkok metropolitan area showed that consumers with different education levels The effect of consumers on the health of consumers in Bangkok. Different the decision to buy healthy foods for consumers in different areas of the product. Statistically significant at the .05 level.

Personal factors with a career The difference in the behavior of different health food choices. In line with the findings of natree jhutom (BE2559), the decision to buy healthy food (Clean Food) of consumers in Amata

Nakorn Industrial Estate In Chonburi province, it was found that the occupation of consumers with different occupations / positions influenced the decision to buy healthy foods (Clean Foods).

Marketing Mix Factor Product quality and price have the overall mean of the significance level is very high. According to research by natree jhutom (BE2559), the decision to buy healthy food (Clean Food) of consumers 
in Amata Nakorn Industrial Estate In Chonburi province, respondents rated the product and price factors at a high level.

Marketing Mix Factor Distribution channel The overall mean of the significance level was moderate. Chumani Maksang Research (BE2559) Study on Dietary Health for Women in Dusit District It was found that the respondents paid attention to the factors of distribution channels. The overall picture was moderate.

Marketing Mix Factor Marketing promotion The overall mean of the significance level was moderate.Comply with the research of lucita ceh.Study on the marketing mix and consumer behavior on food purchasing. For health in Yala (BE2555), the results of marketing mix analysis in marketing promotion. That affects the purchase of health supplements. The overall effect was moderate.

\section{Suggestions from the Study}

A study of marketing mix factors affecting healthy eating behavior. Suggestions from the study are as follows.

1. Entrepreneurs should improve on the beauty of food. Highlighting cleanliness and attention to raw materials and procedures to do meticulous.

2. The entrepreneur should focus on the price. Prices should be appropriate for food and should clearly display prices in menus.

3. Operators should have adequate safety staff. And personality development for staff involved. Human relations Consciousness in continuous service.

4. Entrepreneurs should focus on communicating with customers in a variety of ways. For example, there are additional channels to communicate through social media (Facebook, Instregram, Line)

\section{References}

[1] Mansrinya Mabangku (BE.2558) "The decision to buy healthy food for consumers in Bangkok" Independent Study, Faculty of Philosophy, Postdoctoral Research Management University of North Bangkok, Thailand

[2] Lucita saa (BE.2555) "Marketing mix and consumer behavior on purchasing health supplements in Yala province" Independent Study, MBA Yala Rajabhat University.

[3] Natree chutom (BE.2559) "Factors affecting consumers' decision to buy healthy food (Clean Food) in Amata Nakorn Industrial Estate. Chonburi province" Independent Study This semester is part of the Master of Business Administration Business Administration For Executives College of Commerce Burapha University BE 2559

[4] Chumanii mangsang (BE.2559) "Food consumption of women in Dusit Bangkok" Independent Study, MBA Management University of North Bangkok, 2016

[5] Adul jaturungkul (BE.2552). Marketing concepts and theories. Bangkok: Thammasat University Press.

[6] Howard. (1994). Purchase intention. U.S.A: Department of Psychology.

[7] Kim and Pysarchik. (2000). Purchase intent. International Journal of Retail \& Distribution Management, Vol. 28 Issue: 6.

[8] Fitzsimon and Morwitz. (1996). Purchase intention. The effect of measuring intent on brand-level purchase behavior. Journal of Consumer Research, 23(1), 1-11.

https://doi.org/10.1086/209462

[9] Kotler. (2000). Purchase intent of the consumer. (11th ed.). New Jersey: Prentice Hall.

[10] Putrevu and Lord. (1994). Purchase intention. (5th ed.). Englewood Cliffs, N. J.: Prentice-Hall.

[11] Moven and Minor. (1998). Purchase intention. New Jersey: Prentice-Hall. Pender, N.J.

[12] Miller and Rose. (1995 Cited in Haward, 1994). Purchase intention. New Jersey: Preentice-Hall.

[13] Zeithaml, Berry and Parasuraman. (1990). Purchase intent of the consumer. New York: The Free Press.

[14] Engel, Blackwell and Minird. (1994). Purchase intention. New York: John Wiley and Sons.

[15] Kotler and Armstrong (2002). Purchase intention. New York: John Wiley and Sons. 